\title{
Intra-product Specialization, Technological Dependency and Organization Structure of Heterogeneous Firms
}

\author{
Yang LIU* \\ Business School, East China University of Political Science and Law, 201620, Shanghai, China \\ ddccex@163.com \\ ${ }^{*}$ Corresponding author
}

Keywords: Technological dependency, Organization structure, Heterogeneous firms.

\begin{abstract}
This document integrates GHM model and Nash-bargain game into dynamic game of north-south framework with heterogeneous firms, and uses backward deduction method to resolve the equilibrium organization structure of heterogeneous firms. This document argues that the degree of technological dependency of final-good producers on the intermediate suppliers is the key to the optimal organization structure of heterogeneous final-good produces. It concludes that when final-good producers in head-quarter intensive industry, get intermediate input from home country, and when final-good producers in component intensive industry get intermediate input from foreign the degree of technological dependency of final-good producer on intermediate supplier is very important for his organization structure.
\end{abstract}

\section{Introduction}

Since 1980s, international division of labor has developed from inter-industry to intra-industry and then intra-product. Vertical integration (Helpman, 1984; Helpman and Krugman, 1985) and horizontal integration (Markusen, 1984) is the earliest integration theories [1,2,3]. Then Markusen(2002) created a knowledge capital model incorporating both of them[4]. Motta and Norman(1996), Hanson, Mataloni and Slaughter(2001),Ekholm, Forslid and Markusen(2007) considered that two-countries model cannot explain the whole story of organization structure of firms specifically the export of foreign affiliate to the third country rather than home country and host country[5,6,7]. Ekholm, Forslid and Markusen(2007) created "export-platform" integration model explaining the foreign direct investment from home country to host country companied with the trade between host country and the third country. Yeaple(2003) quantized transportation cost, factor endowment and industry-specific factor intensity to analysis the complex strategies of heterogeneous[8].

At the end of 1990s, lots of empirical studies triggered the review on the assumption of homogeneous firms within industries. Clerides et al.(1996,1998) using clumbia data, Bernard and Jensen(1999,2009), Helpman et al. (2004) and Yeaple(2012)using U.S. data, Bee-Yan et al. (2000) using Taiwan data and Baldwin and $\mathrm{Gu}$ (2003) using Canadian data found that only firms with large scale and high productivity exported in the so-called export industry[9,10,11]. Then Melitz(2003) constructed a Monopolistic competition model with heterogeneous firms which has been a footstone of studies on heterogeneous firms in an industry.[12] Antràs(2003) using U.S. panel data found that intrafirm imports in U.S., is significantly positive correlative with the capital intensity of the exporting industry and capital-labor ratio of the exporting country [13]. And it incorporated GHM with Krugman and Helpman (1985) and constructed a property right model to explain the phenomenon. It concluded that final-good producers in capital intensive sector preferred integration organization and obtained the intermediate input through intra-firm trade in capital abundant country. While final-good producers in labor intensive sector preferred outsourcing organization and obtained the intermediate inputs through arm's-length suppliers in labor abundant country. By extending Antràs (2003), Antràs and Helpman(2004) integrated Melitz(2003) with Helpman, Melitz and Yeaple(2003) into a theoretical framework Setup of model. It concluded that if the final goods are component intensive, the residual control rights of final-good producers are negative correlative 
with their variable profit, and the variable profit is higher under outsourcing organization. If the final goods are head-quarter intensive, the residual control rights of final-good producers are positive correlative with their variable profit, and the variable profit is higher under integration organization.[14]

This document extends Antràs and Helpman(2004) by constructing an theoretical model and arguing that the degree of technological dependency of final-good producer on intermediate supplier also play an important role on the organization structure.

\section{Setup}

There are two countries: home $(\mathrm{H})$ and foreign $(\mathrm{F})$, sharing identical preference of representative consumers, which is given by a C.E.S. utility function

$$
U=\sum_{j=1}^{J} \mu_{j} \log \left(\int_{i} y_{i j}^{\alpha} d i\right)^{1 / \alpha}, \text { s.t. } \quad \mu_{j} E_{L}=\sum_{i} p_{i j} y_{i j}
$$

Where ${ }^{\mu_{j}}$ is the ratio of expenditure on final products in industry $\mathrm{j}$ to total income EL, $\mathrm{L} \in\{\mathrm{H}, \mathrm{F}\}$, and $\sum_{j} \mu_{j}=1 .{ }^{y_{i j}}$ is final good in industry j. $\alpha(0<\alpha<1)$ represents elasticity of substitution between any two final varieties. Demand function of repensentive consumer is

$$
y_{i j}=A_{j} p_{i j}^{-1 /(1-\alpha)}, \text { and } P_{j}=\int_{i} p_{i j}^{-\alpha /(1-\alpha)}
$$

Where $A_{j}=\left(\mu_{j} E_{L} / P_{j}\right)$ is real total expendture in fianl goods of industry $\mathbf{j}$ in country L.

There are two kinds of producer, which are final-good producers ${ }^{Z_{i j}}$ and intermediate input suppliers ${ }^{M_{i j}}$. Production function of final good is

$$
y_{i j}=\theta_{i j}\left[\lambda_{j} h_{i j}^{\rho_{i}}+\left(1-\lambda_{j}\right) m_{i j}^{\rho_{i}}\right]^{1 / \rho_{i}}, \text { and }^{0<\lambda_{j}<1}, \rho_{i}<1
$$

Where ${ }^{\theta_{i j}}$ is productivity of final-good producer ${ }^{Z_{i j}} \cdot h^{h_{j j}}$ and $m_{i j}$ are intermediate inputs. $h_{i j}$ is head-quarter intensive input and produced by ${ }_{i j}$ located in home country. ${ }^{m_{i j}}$ is component intensive input and produced by ${ }^{M_{i j}}$ located in either home country or foreign country. $\lambda_{j}$ represents the intensity of head-quarter input in final-good product ${ }^{y_{i j}} \cdot \rho_{i j}$ represents the elasticity of substitution between $h_{i j}$ and ${ }^{m_{i j}}$, and it represents the degree of technological dependency of $Z_{i j}$ on ${ }^{M_{i j}}$. The larger ${ }^{\rho_{i j}}$ is, the lower the degree of technological dependency of ${ }^{Z_{i j}}$ on ${ }^{M_{i j}}$. And we assume that unit cost of production $h_{i j}$ or $m_{i j}$ is unit local labor hour. In home country wage is 1 and in foreign country wage is $\omega(0<\omega<1)$. Therefore we assume that foreign country has the unit cost advantage.

Since from now on we discuss a particular industry, we drop the index $\mathrm{j}$ from all the variables. Final-good producer ${ }^{Z_{i}}$ can get ${ }^{m_{i}}$ by two means which are integration (V) and outsourcing (O). Based on GHM model, under both organization, final-good producer needs to contract with intermedite supplier and suffers distortion of incomplete contrat, which measn they cannot sign ex-ante enforceable contracts specifying the price and quantity of $m_{i}$. Final-good producer and intermediate supplier bargains over the surplus from the relationship after ${ }^{m}{ }_{i}$ have been produced and delivered. The ex-post bargaining is as a Nash Bargaining game in which the final-good producer obtain a fraction $\beta(0<\beta<1)$ of the ex-post gains from the relationship. Under integration organization, ${ }^{M_{i}}$ is a division of $Z_{i}$ and has no control rights over the ${ }^{m_{i}}$ produced. If 
negotiation fails, ${ }^{Z_{i}}$ can fire ${ }^{M_{i}}$ and seize the ${ }^{m_{i}}$.we assume that firing ${ }^{M_{i}}$ results in a loss of $(1-\phi)_{y_{i}}$, because $Z_{i}$ cannot use the intermediate inputs effectively without cooperation of $M_{i}$. Under outsourcing organization, ${ }^{M_{i}}$ is independent supplier, and a failure to reach an agreement on the distribution of the surplus leaves both parties with no income.

According to Nash bargain game, under integration organization, if they fail to agree on a contract, the outside option of ${ }^{M_{i}}$ is zero. ${ }^{Z_{i}}$ can get ${ }^{\phi_{y}}$ of final-goods, by firing ${ }_{i}$ and his outside option is $\phi^{\alpha} R_{i}$, where $R_{i}=p_{i} y_{i}$ representing the total revenue. In equilibrium, the revenue $Z_{i}$ can get is $\phi^{\alpha} R_{i}+\beta\left(1-\phi^{\alpha}\right) R_{i}=\beta^{\mathrm{V}} R_{i}$ and the revenue ${ }^{M_{i}}$ can get is $(1-\beta)\left(1-\phi^{\alpha}\right) R_{i}=\left(1-\beta^{V}\right) R_{i}$. Under outsourcing organization, ${ }^{M_{i}}$ has the residual right of control over ${ }^{m_{i}}$. If they fail to agree on a contract, outside option of both $Z_{i}$ and ${ }^{M_{i}}$ are zero. In equilibrium, revenue of $Z_{i}$ is $\beta R_{i}=\beta^{0} R_{i}$ and revenue of $M_{i}$ is $(1-\beta) R_{i}=\left(1-\beta^{0}\right) R_{i}$ where $\beta^{V}>\beta^{O}=\beta$.

Upon paying the fixe cost of entry ${ }^{f_{E}}$, and knowing the productivity $\theta_{i}, Z_{i}$ decides whether to exit. If $Z_{i}$ decides to stay and produce fina-good products, he has to bear an extra fixed cost of production ${ }^{f_{Z_{i}}^{L k}}, \mathrm{k} \in\{\mathrm{V}, \mathrm{O}\}$. The fixed cost of production for Intermediate supplier $M_{i}$ is $f_{M_{i}}^{L k}$. Under both integration and outsourcing organization, final-good producer ${ }^{Z_{i}}$ has to contract with intermediate supplier ${ }^{M_{i}}$, while they cannot sign an ex-ante complete contract. After intermediate inputs $m_{i}$ have been produced and delivered, they have deal with second negation. Because $m_{i}$ is customized to ${ }^{y_{i j}}$, in order to avoiding the hold-up problem, ${ }^{Z_{i}}$ has offer $M_{i}$ a $\operatorname{transfer}^{T_{\mathrm{i}}^{\mathrm{Lk}}}$, ex-ante.

First, by maximizing the profits of $Z_{i}$ and $M_{i}$ separately, we can get the output of $h_{i}, m_{i}$ and ${ }^{y_{i}}$. Based on the expected profit, $Z_{i}$ decides the organization structure while ${ }^{M_{i}}$ decides whether to accept the transfer and produce ${ }^{m_{i}}$. Their expected profits are

$$
\begin{aligned}
& \pi_{Z_{\mathrm{i}}}^{L k}=\beta^{k} A^{1-\alpha}\left(y_{i}{ }^{L k}\right)^{\alpha}-h_{i}{ }^{k}-T^{L k}-f_{E}-f_{H}^{L k} \\
& \pi_{M_{i}}^{L k}=\left(1-\beta^{k}\right) A^{1-\alpha}\left(y_{i}{ }^{L k}\right)^{\alpha}-W^{L} m_{i}{ }^{L k}+T_{i}^{L k}-f_{M}^{L k}
\end{aligned}
$$

And by maximizing their expected profit, we can get the output of $h_{i}, m_{i}$ and ${ }^{y_{i}}$ as follow

$$
\begin{aligned}
& h_{i}^{L k}=\left(\lambda \beta^{k}\right)^{\frac{1}{\left(1-\rho_{i}\right)}} A \theta_{i}^{\frac{\alpha}{(1-\alpha)}} \alpha^{\frac{1}{(1-\alpha)}}\left[\lambda^{\frac{1}{(1-\rho)}}\left(\beta^{k}\right)^{\frac{\rho_{i}}{\left(1-\rho_{i}\right)}}+(1-\lambda)^{\frac{1}{\left.1-\rho_{i}\right)}}\left(\frac{1-\beta^{k}}{W^{L}}\right)^{\frac{\rho_{i}}{1-\rho_{i}}}\right]^{\frac{\alpha-\rho_{i}}{\rho_{i}(1-\alpha)}} \\
& m_{i}^{L k}=\left[\frac{(1-\lambda)\left(1-\beta^{k}\right)}{W^{L}}\right]^{\frac{1}{\left(1-\rho_{i}\right)}} A \theta_{i}^{\frac{\alpha}{(1-\alpha)}} \alpha^{\frac{1}{(1-\alpha)}}\left[\lambda^{\frac{1}{\left(1-\rho_{i}\right)}}\left(\beta^{k}\right)^{\frac{\rho_{i}}{\left(1-\rho_{i}\right)}}+(1-\lambda)^{\frac{1}{\left(1-\rho_{i}\right)}}\left(\frac{1-\beta^{k}}{W^{L}}\right)^{\frac{\rho_{i}}{1-\rho_{i}}}\right]^{\frac{\alpha-\rho_{i}}{\rho_{i}(1-\alpha)}} \\
& y_{i}^{L k}=A \theta_{i}^{\frac{\alpha}{(1-\alpha)}} \alpha^{\frac{1}{(1-\alpha)}}\left[\lambda^{\frac{1}{\left(1-\rho_{i}\right)}}\left(\beta^{k}\right)^{\frac{\rho_{i}}{\left(1-\rho_{i}\right)}}+(1-\lambda)^{\frac{1}{\left(1-\rho_{i}\right)}}\left(\frac{1-\beta^{k}}{W^{L}}\right)^{\frac{\rho_{i}}{1-\rho_{i}}}\right]^{\frac{1-\rho_{i}}{\rho_{i}(1-\alpha)}}
\end{aligned}
$$


Based on the free entry condition for ${ }^{M_{i}}$, we can get the transfer $T_{i}^{L k}$ as follow

$$
T_{i}^{L k}=-\left(1-\beta^{k}\right) A^{1-\alpha}\left(y_{i}^{L k}\right)^{\alpha}+W^{L} m_{i}^{L k}+f_{M}^{L k}
$$

To incorporate (6)-(9) into (4), we gan get the equilibrium profit of $Z_{i}$ is

$$
\pi_{Z_{i}}^{L k}=A \alpha^{\frac{\alpha}{(1-\alpha)}} \Theta_{i}\left(\lambda^{\frac{1}{\rho_{i}}} \beta^{k}\right)^{\frac{\alpha}{(1-\alpha)}}\left(1+\Phi_{i}{ }^{L k}\right)^{\frac{\alpha-\rho_{i}}{\rho_{i}(1-\alpha)}}\left[1-\alpha \beta^{k}+\Phi_{i}{ }^{L k}\left(1-\alpha+\alpha \beta^{k}\right)\right]-f^{L K}-f_{E}
$$

Where $\Theta_{i}=\theta_{i}^{\frac{\alpha}{(1-\alpha)}}, \Phi_{i}^{L k}=\left(\frac{1-\beta^{k}}{\beta^{k} W^{L}}\right)^{\rho_{i} /\left(1-\rho_{i}\right)}\left(\frac{1-\lambda}{\lambda}\right)^{1 /\left(1-\rho_{i}\right)}, f^{L k}=f_{Z}^{L k}+f_{M}^{L k}$.

\section{Organization structure analysis}

There are two kinds of organization structure, which are integration and outsourcing. To derivative the profit of ${ }^{Z_{i}}$ with $\beta^{k}$, we have

$$
\left.\frac{\partial \pi_{Z_{i}}^{L k}}{\partial \beta^{k}}=A \alpha^{\frac{1}{1-\alpha}} \Theta_{i} \frac{\left(\beta^{k} \lambda^{\frac{1}{\rho_{i}}} \frac{\alpha}{1-\alpha}\right.}{\beta^{k}}\left(1+\Phi_{i}^{L k}\right)^{\frac{\alpha-\rho_{i}}{\rho_{i}(1-\alpha)}}\right)^{-1}\left[\frac{1-\beta}{1-\alpha}+\frac{1-2 \beta}{\left(1-\rho_{i}\right)(1-\beta)} \Phi_{i}^{L k}-\frac{\beta^{2}}{(1-\alpha)(1-\beta)} \Phi_{i}^{L k^{2}}\right]
$$

Based on (11), we conclude that, the relationship between the profit of $Z_{i}$ and the $\beta^{k}$ depends on the expression in the square brackets, which is a quadratic function of $\Phi_{i}{ }^{L k}\left(\Phi_{i}{ }^{L k} \geq 0\right)$ and in $(0$, $+\infty)$ there is a unique solution

$$
\Phi_{0}=\frac{1}{2}\left(\frac{1}{\beta^{k}}\right)^{2}\left\{\frac{\left(1-2 \beta^{k}\right)(1-\alpha)}{\left(1-\rho_{i}\right)}+\sqrt{\frac{\left(1-2 \beta^{k}\right)^{2}(1-\alpha)^{2}}{\left(1-\rho_{i}\right)^{2}}+\left[2 \beta^{k}\left(1-\beta^{k}\right)\right]^{2}}\right\} \text {. }
$$

When $\Phi_{i}{ }^{L k}>\Phi_{0}$,we have $\left(\partial \pi_{Z_{i}}^{L k} / \partial \beta^{k}\right)<0$, which means profit of $Z_{i}$ is larger under outsourcing organization. When $\Phi_{i}{ }^{L k}<\Phi_{0}$, we have $\left(\partial \pi_{Z_{i}}^{L k} / \partial \beta^{k}\right)>0$, which means profit of $Z_{i}$ is larger under integration organization. Furthermore, the relationship between $\Phi_{i}{ }^{L k}$ and $\Phi_{0}$ depends on the degree of technological dependency ${ }^{\rho_{i}}$, the intensity of head-quarter inputs $\lambda$ and cost advantage in foreign country ${ }^{\omega}$.

In head-quarter intensive industry, if $Z_{i}$ gets ${ }^{m_{i}}$ from ${ }^{M_{i}}$ located in foreign country, the degree of technological dependency has no effect on his organization. Under integration organization he can gain higher profit comparing to outsourcing organization. If $Z_{i}$ gets ${ }^{m_{i}}$ from ${ }^{M_{i}}$ located in home country, $Z_{i}$ with higher degree of technological dependency on $M_{i}$ will choose outsourcing organization and $Z_{i}$ with lower degree of technological dependency on $M_{i}$ will choose integration organization.

In component intensive industry, if $Z_{i}$ gets ${ }^{m_{i}}$ from ${ }^{M_{i}}$ located in foreign country, ${ }^{Z_{i}}$ with higher degree of technological dependency on $M_{i}$ will choose integration organization and $Z_{i}$ with lower degree of technological dependency on $M_{i}$ will choose outsourcing organization. If $Z_{i}$ gets ${ }^{m_{i}}$ from ${ }^{M_{i}}$ located in home country, the degree of technological dependency has no effect on his organization. Under outsourcing organization he can gain higher profit comparing to integration organization. 


\section{Summary}

This document integrates GHM model and Nash-bargain game into dynamic game of north-south framework with heterogeneous firm, and uses backward deduction method to resolve the equilibrium organization structure of heterogeneous firms. This document argues that the degree of technological dependency of final-good producers on the intermediate suppliers is the key to the optimal organization structure of heterogeneous final-good produces. It concludes that when final-good producers in head-quarter intensive industry, get intermediate input from home country, and when final-good producers in component intensive industry get intermediate input from foreign the degree of technological dependency of final-good producer on intermediate supplier is very important for his organization structure.

\section{Reference}

[1] Helpman E., A Simple Theory of International Trade with Multinational Corporations, Journal of Political Economy. 92 (1984) 451-47.

[2] Helpman E, Krugman P R., Market Structure and Foreign Trade: Increasing Returns, Imperfect Competition, and the International Economy, Cambridge(1985) MIT Press.

[3] Markusen J R. Multinationals, Multi-Plant Economies, and the Gains from Trade, Journal of International Economics. 16(1984) 205-226.

[4] Markusen J R., Multinational Firms and the Theory of International Trade, MIT Press (2002).

[5] Motta M, Norman G., Does Economic Integration Cause Foreign Direct Investment?, International Economic Review. 37(1996) 757-783.

[6] Hanson G H, Mataloni R J, Slaughter M J., Expansion Strategies of U.S. Multinational Firms, BEA Working Papers 0002 (2001).

[7] Ekholm K, Forslid R, Markusen J R., Export-Platform Foreign Direct Investment, Journal of the European Economic Association. 5(2007) 776-795.

[8] Yeaple, S., The Complex Integration Strategies of Multinationals and Cross Country Dependencies in the Structure of Foreign Direct Investment, Journal of International Economics. 60(2003) 293-314.

[9] Clerides S K, Lach S, Tybout J R., Is Learning By Exporting Important? Micro-Dynamic Evidence from Colombia, Mexico, and Morocco, Quarterly Journal of Economics. 113(1998) 903-947.

[10]Bernard A B, Jensen B J., Exceptional exporter performance: cause, effect, or both? , Journal of International Economics. 47(1999) 1-25.

[11]Helpman E, Melitz J M, Yeaple S R., Export versus FDI with Heterogeneous Firms, American Economic Review. 94(2004) 300-316.

[12]Melitz M., The Impact of Trade on Intra-Industry Reallocations and Aggregate Industry Productivity, Econometrica, 71(2003) 1695-1725.

[13]Antràs, Pol., Firms, Contracts, and Trade Structure, Quarterly Journal of Economics 118(2003) 1375-1418.

[14]Antràs, Pol., Firms, Contracts, and Trade Structure, Quarterly Journal of Economics 118(2003) 1375-1418. 